\title{
Séparation chromatographique de peptides issus de l'hydrolyse enzymatique de protéines de lactosérum et de caséines *
}

\author{
Frédérique TOURAINE, G. BRULÉ, J.L. MAUBOIS \\ INRA, Laboratoire de Recherches de Technologie laitière, 65, rue de Saint-Brieuc, \\ 35042 Rennes Cedex, France
}

\section{Résumé}

Un fractionnement de peptides issus de l'hydrolyse enzymatique en réacteur à membranes des différentes protéines laitières est réalisé par chromatographie frontale, technique facile à mettre en œuvre à grande échelle et de faible coût économique.

Deux fractions (I et II) sont obtenues sur support échangeur d'anions à partir des peptides de lactosérum, des peptides de caséines, des peptides phosphorylés, des peptides non phosphorylés et des caséinomacropeptides.

Les peptides de la fraction II sont élués en chromatographie CLHP en phase inverse dans la zone la plus hydrophobe du gradient. Cette fraction contient les peptides de $\mathrm{pH}$ isoélectriques les plus bas. Les analyses en chromatographie CLHP d'exclusion montrent que ce sont également les plus longs, ce qui expliquerait leur élution tardive en chromatographie phase inverse.

Les minéraux présents dans les mélanges initiaux $\left(\mathrm{Ca}^{2+}, \mathrm{Mg}^{2+}, \mathrm{Na}^{+}, \mathrm{K}^{+}\right)$sont élués dans les premières fractions.

La fraction II issue des phosphopeptides est très enrichie en phosphore ; sa teneur est 4 fois supérieure à celle de la solution phosphopeptidique initiale.

La fraction II des caséinomacropeptides s'est accrue de $40 \%$ en acide N-acétylneuraminique par rapport au mélange initial.

Mots clés : Peptides - Lait - Lactosérum - Caséine - Chromatographie - Fractionnement.

\section{Summary}

\section{Chromatographic separation of peptides stemming from splitting of whey proteins and caseins}

By chromatographic fractionation of peptides from milk proteins, on an anionexchange support, two fractions (I and II) were obtained. This separation was carried out on whey peptides, casein peptides, peptides with or without organic phosphorus and caseinomacropeptides.

\footnotetext{
* Ce travail a été effectué dans le cadre d'une collaboration de Recherches entre l'INRA et la Société Sopharga.
} 
The peptides of the second fraction were eluted in reverse phase chromatography in the most hydrophobic zone of the gradient. Fraction II contained peptides with a low isoelectric $\mathrm{pH}$ which were also the longest peptides, confirmed by chromatography HPLC of exclusion.

Most of the minerals of the initial peptide mixtures $\left(\mathrm{Ca}^{2+}, \mathrm{Mg}^{2+}, \mathrm{Na}^{+}, \mathrm{K}^{+}\right)$were eluted in the first fraction.

Fraction II from the phosphopeptides was enriched in phosphorus ; its content was 4 times higher than the initial phosphopeptide solution.

The content in $\mathrm{N}$-acetylneuraminic acid of fraction II of caseinomacropeptides was increased by $40 \%$ in comparison with the initial mixture.

Key words : Peptides - Milk - Whey - Casein - Chromatography - Fractionation.

\section{Introduction}

Il est maintenant bien admis que le transport intestinal des oligopeptides est nettement plus efficace que celui des acides aminés libres (SLEISINGER et al., 1976 ; Silk et al., 1980 ; Rerat et al., 1984). Cette efficacité serait due à une minimisation des phénomènes de compétition au niveau des sites d'absorption par rapport aux acides aminés libres (RERAT et al., 1984).

Sur la base de ces résultats, les techniques de soins intensifs des patients atteints de troubles nutritionnels graves tels que ceux qui résultent de l'impossibilité d'alimentation ou de carences en certaines enzymes de la digestion ont considérablement évolué ces dernières années.

A l'alimentation parentérale (intraveineuse) qui assurait seulement la satisfaction des besoins nutritifs du malade avec souvent des complications secondaires (problèmes septiques) a succédé l'alimentation entérale (LEVY, 1976) qui induit en plus une véritable réadaptation fonctionnelle de la muqueuse digestive.

La mise en œuvre de l'alimentation entérale requiert l'élaboration de solutions nutritives équilibrées en lipides, protides, glucides, vitamines et minéraux, bien adaptées au déséquilibre métabolique ou/et fonctionnel de chaque malade (Mendy, 1976). De par leur composition en acides aminés indispensables, leur facilité d'obtention à l'état purifié, les protéines de lait et de lactosérum sont des substrats de choix pour la préparation de solutions peptidiques entrant dans la composition des produits destinés à l'alimentation entérale (Maubois et al., 1979 ; Brulé et al., 1981).

De telles solutions sont préparées aisément par la technologie du réacteur enzymatique à membrane comme cela a été proposé par RogER (1979) à partir de concentrés de protéines de lactosérum et par Brulé et al. (1981) à partir de lait ou de caséinates. La protéolyse enzymatique obtenue dans cette technologie est très similaire à celle réalisée in vivo tant sur le plan de la cinétique que sur celui de la nature des produits obtenus. Mais, bien que ces solutions peptidiques soient à la fois mieux absorbées par la muqueuse intestinale (RERAT et al., 1984) et qu'elles conduisent à une régénération ou à une hypertrophie compensatrice des segments intestinaux restants (MENDY, 1984), il 
apparaît nécessaire de rechercher une séparation plus fine des mélanges peptidiques quittant le réacteur. En effet, il apparaît comme probable que ces mélanges contiennent des séquences peptidiques induisant directement ou indirectement, à partir des récepteurs intestinaux, des actions de régulation anticipative : sécrétions enzymatiques et hormonales, orientations des carrefours métaboliques (MENDY, 1984), ou ayant par elles-mêmes, une action physiologique comme par exemple, la $\beta$-casomorphine (Brantl et Henschen, 1979).

De telles séquences sont à rechercher parmi les fractions présentant des compositions originales: peptides glycosylés, peptides hydrophobes, peptides phosphorylés, peptides riches en tel ou tel acide aminé indispensable. Plusieurs méthodologies de séparation basées sur la charge électrique nette, l'affinité pour l'eau, la taille, sont envisageables pour le fractionnement des mélanges peptidiques. Seules, quelques-unes sont actuellement susceptibles d'extrapolation industrielle rapide. La chromatographie sur résines échangeuses d'ions faisant partie de ces dernières, nous avons, au cours du présent travail, examiné les possibilités qu'elle offrait d'obtenir des mélanges de peptides plus homogènes quant à leurs caractéristiques biochimiques et donc, éventuellement, à même de convenir à des besoins nutritionnels ou physiologiques précis.

\section{Matériels et méthodes}

\section{A. Peptides}

Les peptides de lactosérum (PLS) étaient fournis par la Société SOPHARGA; ils étaient préparés selon le procédé décrit par MAUBoIs et al. (1979).

Les peptides de caséinate (PC) et leurs diverses fractions, phosphopeptides (PP), peptides non phosphorylés (PNP) et caséinomacropeptides (CMP), étaient fournis par la même société. Ils étaient préparés selon le procédé décrit par BRulé et al. (1981). La composition en acides aminés des différentes fractions peptidiques est rapportée tableau 1. Les différents peptides ainsi utilisés étaient constitués de 2 à 5 acides aminés et leur poids moléculaire inférieur à 600 (ROGER, 1979 ; BRULÉ, 1981).

\section{B. Méthodes de fractionnement}

Nous avons utilisé un support échangeur d'anions faibles (Fractogel TSK DEAE 650) commercialisé par IBF, 92390 Villeneuve-la-Garenne. La colonne chromatographique de $1 \mathrm{~m}$ de hauteur et $2 \mathrm{~cm}$ de diamètre était alimentée et éluée à un débit de $80 \mathrm{ml} / \mathrm{h}$ à température ambiante; la détection était réalisée à l'aide d'un spectrophotomètre UV à $254 \mathrm{~nm}$. Après conditionnement avec de l'eau distillée, la colonne était alimentée en continu avec une solution de peptides (10 à $20 \mathrm{~g} / \mathrm{l}$ ). Les peptides non retenus par le support étaient collectés pendant un temps prédéterminé variant de 1 à 2 heures. La colonne était ensuite rincée à l'eau distillée puis une élution réalisée avec une solution d'HCl $(0,1 \mathrm{~N})$ permettait le relargage des peptides retenus sur le support 
chromatographique. Lorsque toute la fraction azotée était éluée, on procédait à un rinçage à l'eau distillée avant de recommencer un nouveau cycle.

\section{Méthodes analytiques}

Les teneurs en azote total ont été déterminées par microkjeldahl sur un auto-analyseur TECHNICON.

Le dosage des acides aminés était réalisé sur un analyseur BECKMAN.

Le dosage des minéraux était réalisé par spectrométrie d'absorption atomique selon Brulé et al. (1974).

Le dosage de l'acide $N$-acétylneuraminique (NANA) était réalisé selon la méthode de WARrEN (1959).

Le phosphore était dosé selon la méthode FIL (norme $\mathrm{n}^{\circ} 33$ ).

Les fractions peptidiques étaient caractérisées par chromatographie d'exclusion et en phase inverse avec un équipement VARIAN.

- Chromatographie d'exclusion

Nous avons utilisé une colonne de $30 \mathrm{~cm}$ contenant une silice poreuse greffée $\mathrm{Si}\left(\mathrm{CH}_{2}\right)_{3}-\mathrm{O}-\mathrm{CH}_{2}-\mathrm{CHOH}-\mathrm{CH}_{2} \mathrm{OH}$ (gel Micropak TSK type N). L'élution isocratique était réalisée avec un tampon phosphate : $\mathrm{Na}_{2} \mathrm{HPO}_{4}(1,38 \mathrm{~g} / \mathrm{l})$ ajusté à $\mathrm{pH} 2,2$ avec $\mathrm{H}_{3} \mathrm{PO}_{4}$ concentré, à un débit de $0,8 \mathrm{ml} / \mathrm{mn}$. La détection était effectuée à $254 \mathrm{~nm}$.

\section{- Chromatographie phase inverse}

Nous avons utilisé une colonne de $30 \mathrm{~cm}$ de long et $4 \mathrm{~mm}$ de diamètre contenant de la silice greffée avec des chaînes carbonées C18 (Micropak MCH$10,10 \mu \mathrm{m})$. Le gradient d'élution était réalisé selon le schéma suivant :

A : solution acide $\mathrm{H}_{3} \mathrm{PO}_{4}(0,7 \mathrm{ml} / 1)$ soit $0,01 \mathrm{M}$,

B : solution $\mathrm{H}_{2} \mathrm{O} /$ méthanol $(20 / 80)$ acidifiée avec $\mathrm{H}_{3} \mathrm{PO}_{4}(0,7 \mathrm{ml} / \mathrm{l})$.

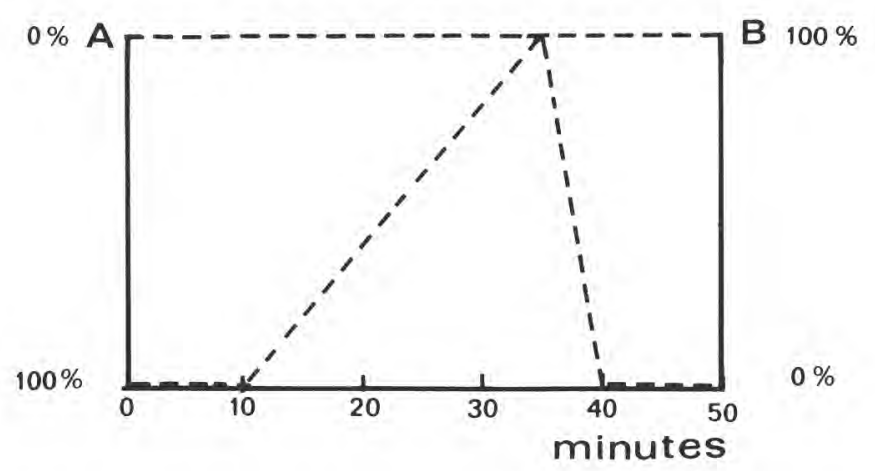

Le débit d'élution était de $0,8 \mathrm{ml} / \mathrm{mn}$; les fractions éluées étaient dosées par l'orthophtalaldéhyde et détectées à l'aide d'un fluorimètre SOPARES à $442 \mathrm{~nm}$. 


\section{Résultats}

\section{A. Séparation des peptides}

Le profil chromatographique type que nous avons obtenu pour chacune des matières premières étudiées (PLS, PC, PP, PNP et CMP) est représenté sur la figure 1. Dans chaque cas, nous avons collecté une fraction I constituée de peptides ayant peu d'affinité avec le support et donc non retenus et une fraction II composée de peptides retenus par le support et élués par $\mathrm{HCl} \mathrm{N/10.}$

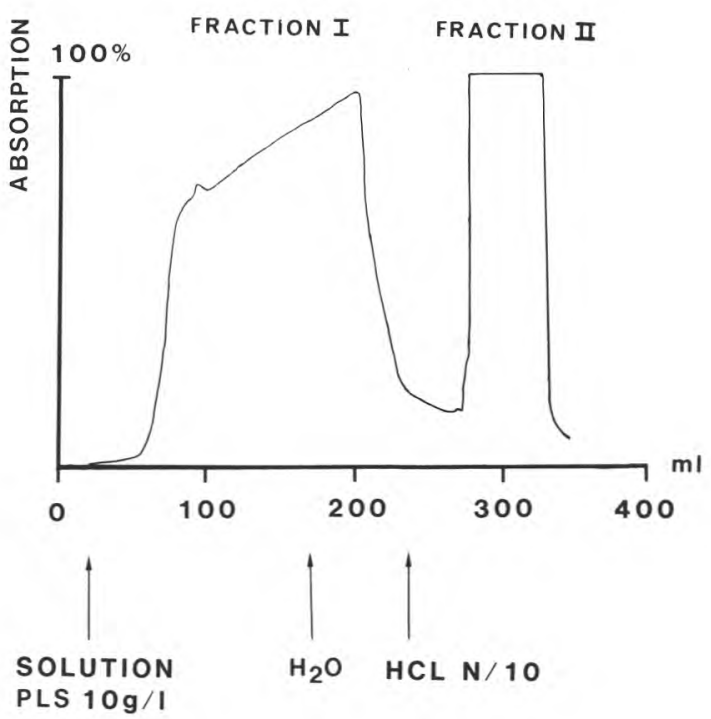

Fig. 1

Profil chromatographique obtenu au cours du fractionnement de peptides de lactosérum (PLS) sur support échangeur d'anions.

Elution profile obtained during whey peptide separation on an anion-exchange support.

Lorsque l'éluat avait la même composition que la solution de départ (ce qui était déterminé par chromatographie analytique d'exclusion ou en phase inverse), on considérait que la colonne était saturée.

Un rinçage à l'eau puis l'élution de la seconde fraction étaient alors réalisés. Compte tenu de la bonne reproductibilité des chromatogrammes, il était possible de programmer l'élution en temps ou en volume. 


\section{B. Analyse des fractions obtenues}

\section{Caractérisation physicochimique}

a) Composition en acides aminés

Dans le tableau 1 sont rapportées les teneurs en \% de chacun des acides aminés dans les mélanges peptidiques initiaux. Les histogrammes de la figure 2 représentent les aminogrammes correspondant aux fractions I et II des PLS (2a), PC (2b), PP (2c), PNP (2d), CMP (2e).

TABLEAU 1

Composition en acides aminés (en g/100 g) des mélanges de peptides de caséine (PC), phosphopeptides (PP), peptides non phosphorylés (PNP), peptides de lactosérum (PLS) et caséinomacropeptides (CMP)

Aminoacid composition ( $/ 100 \mathrm{~g}$ ) of initial mixtures of casein peptides (PC), phosphopeptides (PP), peptides without organic phosphorus (PNP), whey peptides (PLS) and caseinomacropeptides (CMP)

\begin{tabular}{c|c|c|r|r|r}
\hline AA (\%) & PC & PP & PNP & PLS & CMP \\
\hline ASP & 6.82 & 7.70 & 6.30 & 11.40 & 7.96 \\
THR & 3.97 & 5.05 & 3.52 & 5.98 & 13.78 \\
SER & 5.38 & 9.23 & 8.25 & 4.68 & 6.64 \\
GLU & 21.26 & 28.36 & 18.77 & 17.50 & 20.25 \\
PRO & 10.55 & 8.37 & 13.71 & 5.35 & 11.49 \\
GLY & 1.77 & 1.93 & 2.56 & 1.93 & 1.09 \\
ALA & 2.95 & 2.86 & 3.13 & 5.39 & 5.65 \\
CYS & - & - & - & 0.98 & - \\
VAL & 6.37 & 6.77 & 5.96 & 5.16 & 7.98 \\
MET & 2.72 & 2.14 & 1.46 & 1.96 & 1.63 \\
ILE & 4.94 & 6.82 & 4.13 & 6.13 & 9.13 \\
LEU & 9.02 & 6.94 & 9.24 & 11.01 & 3.45 \\
TYR & 5.18 & 2.13 & 5.89 & 3.31 & 1.15 \\
PHE & 4.85 & 2.53 & 5.37 & 3.29 & 1.18 \\
HIS & 2.85 & 1.75 & 3.15 & 2.16 & 0.97 \\
LYS & 7.72 & 4.73 & 8.80 & 10.62 & 6.21 \\
ARG & 3.55 & 2.54 & 3.80 & 2.78 & 1.34 \\
\hline
\end{tabular}

Les deux fractions obtenues apparaissent différentes par leur composition. Les fractions I sont en effet enrichies en arginine (71\%), phénylalanine (PP : $70 \%$ ), histidine (PC : $100 \%$ ), méthionine (PP : $33 \%$ ), proline (PLS : $80 \%$ ) par rapport aux diverses matières premières, donc pour une large part en acides aminés basiques. 
Les fractions II par contre riches en acides aminés à caractère acide, présentent une augmentation de l'acide aspartique (PC : $42 \%$, PNP : $58 \%$ ) et de l'acide glutamique (PP : $240 \%$, PNP : $52 \%$, PLS : $37 \%$ ) ainsi qu'en sérine (PC : $37 \%$, PP : $41 \%$ ).

Le rapport des acides aminés basiques (Arg-Lys-His) sur les acides aminés acides (Glu-Asp) dans les fractions II est toujours inférieur à celui des fractions I et ceci pour chaque matière première (tabl. 2). Le paramètre de Marchalonis et Weltman (1971) permet d'évaluer les homologies et les différences entre les diverses fractions. Il est défini comme la somme des carrés des différences de composition en acides aminés (j) des fractions dans lesquelles $\mathrm{i}$ et $\mathrm{k}$ représentent respectivement le mélange initial et le mélange peptidique étudié :

$$
S \Delta Q=\Sigma\left(X_{i, j}-X_{k, j}\right)^{2}
$$

\section{TABleau 2}

Rapport des teneurs en acides aminés basiques sur les teneurs en acides aminés acides des peptides totaux (PT) et de chaque fraction I et II obtenues après fractionnement chromatographique sur un support échangeur d'anions

Ratio of basic amino acid content on acid amino acid content of total peptides (PT) and of each fraction I and II obtained after chromatographic separation on an anion-exchange support

\begin{tabular}{l|c|c}
\hline \multicolumn{1}{c|}{ Nature des peptides } & & $\frac{\text { A.A. basiques }}{\text { A.A. acides }}$ \\
\hline \multirow{3}{*}{ Peptides de lactosérum } & PT & 0,54 \\
& I & 0,97 \\
& II & 0,26 \\
\hline \multirow{3}{*}{ Peptides de caséine } & PT & 0,50 \\
& I & 0,90 \\
Phosphopeptides & II & 0,21 \\
\hline \multirow{3}{*}{ Peptides non phosphorylés } & PT & 0,24 \\
& I & 0,55 \\
& II & 0,13 \\
\hline
\end{tabular}

La fraction I des PP $(\mathrm{S} \Delta \mathrm{Q}=209,5)$ et les fractions II des PC $\mathrm{S} \Delta \mathrm{Q}=124,6)$ et $\mathrm{PNP}(\mathrm{S} \Delta \mathrm{Q}=226,14)$ présentent les plus grandes différences en acides aminés par rapport au mélange initial (tabl. 3a). Le tableau 3b réunit les $\mathrm{S} \Delta \mathrm{Q}$ calculés entre les fractions I et II. 

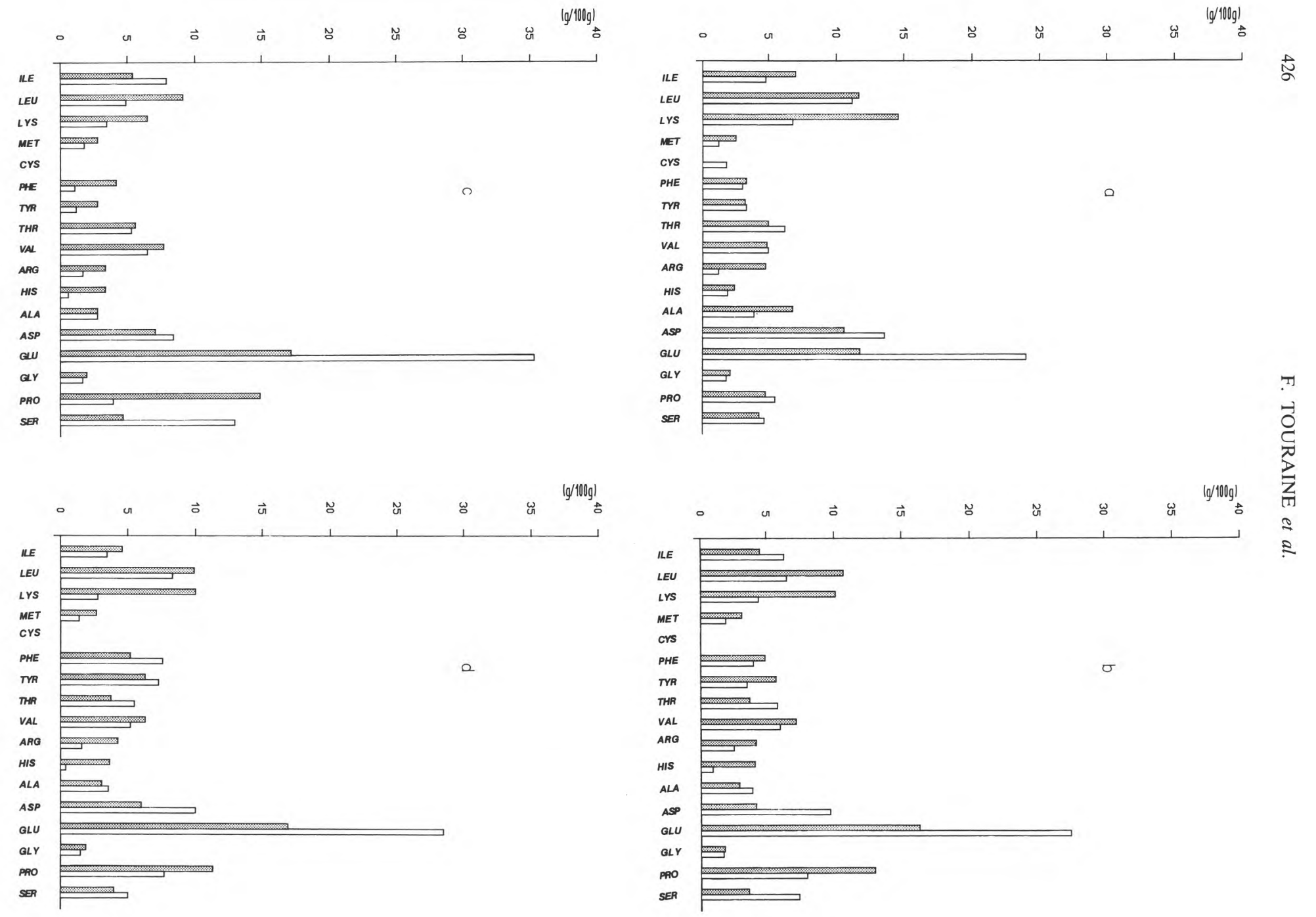


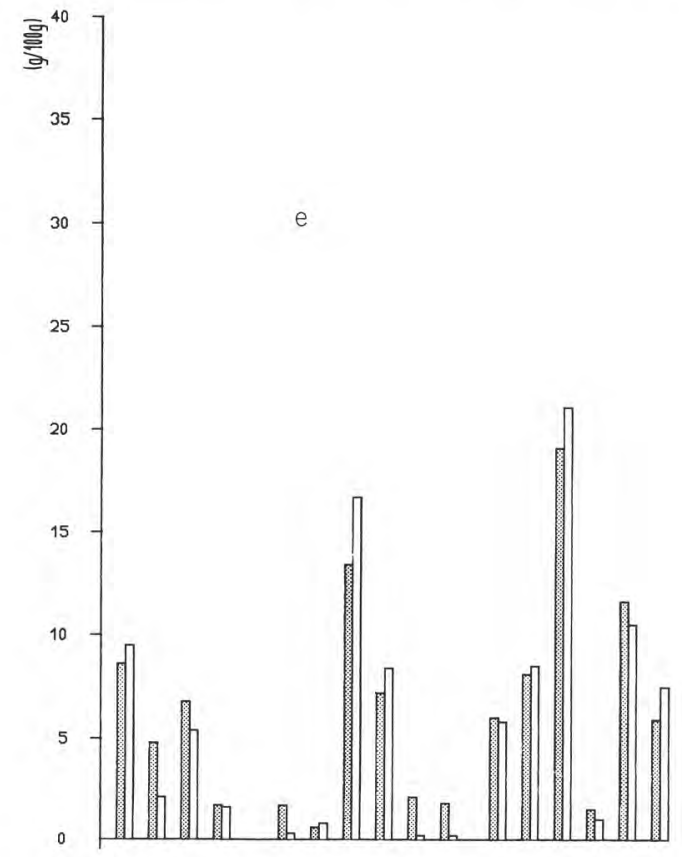

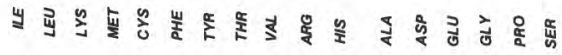

Fig. 2

Teneurs en acides aminés ( $\mathrm{g} / 100 \mathrm{~g}$ ) des fractions I et II des peptides de lactosérum (2a), des peptides de caséine (2b), des phosphopeptides (2c), des peptides non phosphorylés (2d) et des caséinomacropeptides (2e).

$\gtrless$ Fraction I, $\square$ Fraction II.

Amino-acid contents $(\mathrm{g} / 100 \mathrm{~g})$ of fractions $I$ and II of whey peptides $(2 a)$, casein peptides (2b), phosphopeptides (2c), non phosphorylated peptides ( $2 d)$ and caseinomacropeptides $(2 e)$.

济 Fraction I, $\square$ Fraction II.

Par le calcul des $\mathrm{S} \Delta \mathrm{Q}$ entre les fractions I et II (tabl. 3b), la différence de composition en acides aminés des peptides fractionnés est évaluée ; elle est d'autant plus grande que la valeur s'éloigne de zéro. Les distances entre les fractions I et II des PLS, PC, PNP sont élevées (PLS, S $\Delta$ Q (I, II) = 247,9 ; $\mathrm{PC}, \mathrm{S} \Delta \mathrm{Q}(\mathrm{I}, \mathrm{II})=279,5 ; \mathrm{PNP}, \mathrm{S} \Delta \mathrm{Q}(\mathrm{I}, \mathrm{II})=257)$; une valeur très forte est obtenue dans le cas des PP dont le S $\Delta \mathrm{Q}$ (I, II) est égal à 585,3. Les fractions I et II des CMP sont par contre très proches et diffèrent peu par leur composition en acides aminés [S $\Delta \mathrm{Q}(\mathrm{I}, \mathrm{II})=38,8]$. 


\section{TABLEAU 3}

Evaluation des $S \Delta Q$ des fractions $I$ et $I I$ des $P L S, P C, P N P, P P$ et $C M P$, obtenues après fractionnement chromatographique sur un support échangeur d'anions, par rapport au mélange initial (a) et entre elles (b)

$S \Delta Q$ evaluation of fractions $I$ and II of PLS, PC, PNP, PP and CMP, obtained after chromatographic separation on an anion-exchange support, in comparison with the initial mixture (a) and between I and II (b)

(a)

\begin{tabular}{l|c|c}
\hline \multicolumn{1}{c|}{ Nature des peptides } & \multicolumn{2}{c}{$\mathrm{S} \Delta \mathrm{Q} / \mathrm{au}$ mélange initial } \\
\hline Fractions & I & II \\
\hline Peptides de lactosérum & 59,2 & 69,7 \\
\hline Peptides de caséine & 63,1 & 124,6 \\
\hline Phosphopeptides & 209,5 & 96,0 \\
\hline Peptides non phosphorylés & 32,0 & 226,1 \\
\hline Caséinomacropeptides & 7,4 & 16,7 \\
\hline
\end{tabular}

(b)

\begin{tabular}{l|c}
\hline \multicolumn{1}{c|}{ Nature des peptides } & S $\Delta$ Q entre I et II \\
\hline Peptides de lactosérum & 247,9 \\
\hline Peptides de caséine & 279,5 \\
\hline Phosphopeptides & 585,3 \\
\hline Peptides non phosphorylés & 257,9 \\
\hline Caséinomacropeptides & 38,8 \\
\hline
\end{tabular}

b) Composition minérale

- Teneurs en $\mathrm{Ca}, \mathrm{Mg}, \mathrm{Na}, \mathrm{K}$

Les teneurs en sodium, calcium, magnésium et potassium exprimées en g/ $\mathrm{kg}$ des PLS, PC, PP, PNP et CMP et des fractions chromatographiques I et II de ces peptides sont rapportées dans le tableau 4. La composition minérale des produits révèle une teneur plus élevée en $\mathrm{Ca}, \mathrm{K}, \mathrm{Na}, \mathrm{Mg}$ dans les produits initiaux et les fractions I que dans la fraction II. Les fortes teneurs en $\mathrm{Na}$ de la fraction II des peptides de lactosérum (PLS) et peptides non phosphorylés (PNP) sont dues à une neutralisation à la soude réalisée avant lyophilisation. 


\section{TABLEAU 4}

Teneurs en $\mathrm{Ca}, \mathrm{Mg}, \mathrm{Na}, \mathrm{K}$ des produits initiaux et des fractions $I$ et II obtenues par fractionnement sur échangeur d'anions des peptides de lactosérum (PLS), peptides de caséine $(P C)$, phosphopeptides $(P P)$, peptides non phosphorylés $(P N P)$ et caséinomacropeptides (CMP)

$\mathrm{Ca}, \mathrm{Mg}, \mathrm{Na}$ and $\mathrm{K}$ contents of initial products on an anion-exchange support and fractions $I$ and II, obtained by separation of whey peptides (PLS), casein peptides $(P C)$, phosphopeptides $(P P)$, peptides without organic phosphorus (PNP) and caseinomacropeptides (CMP)

(a)

\begin{tabular}{l|c|c|r|r|r}
\hline & \multirow{3}{*}{} & & \multicolumn{3}{|c}{ Teneur en minéraux (g/kg de poudre) } \\
\cline { 3 - 6 } Peptides totaux & & Ca & Mg & Na & \multicolumn{1}{c}{$\mathrm{K}$} \\
\cline { 3 - 6 } & PLS & 2,85 & 0,25 & 7,60 & 7,75 \\
& PC & 0,60 & 0,05 & 12,50 & 14,50 \\
& PP & 70,00 & 0,25 & 4,75 & 3,35 \\
& PNP & 10,80 & 0,14 & 23,00 & 21,60 \\
& CMP & 6,00 & 0,50 & 17,50 & 1,15 \\
\hline \multirow{5}{*}{ Fractions I } & PLS & 5,14 & 0,50 & 19,90 & 13,26 \\
& PC & 1,32 & 0,11 & 22,50 & 16,00 \\
& PP & 54,00 & 0,38 & 16,00 & 10,00 \\
& PNP & 14,56 & 0,14 & 28,00 & 20,90 \\
& CMP & 15,00 & 1,80 & 43,00 & 3,00 \\
\hline \multirow{5}{*}{ Fractions II } & PLS & 0,08 & 0,00 & 65,00 & 0,04 \\
& PC & 0,10 & 0,00 & 0,35 & 0,19 \\
& PP & 65,00 & 0,08 & 0,05 & 0,01 \\
& PNP & 0,07 & 0,00 & 2,00 & 0,16 \\
& CMP & 0,72 & 0,06 & 1,62 & 0,10 \\
\hline
\end{tabular}

\section{- Teneurs en phosphore}

Nous avons déterminé le degré de phosphorylation et donc le taux de phosphosérines des peptides de caséines et des fractions I et II des phosphopeptides (tabl. 5). La fraction I s'est avérée très pauvre en phosphore. L'évaluation du taux de phosphore global de la fraction II des phosphopeptides par rapport aux taux trouvés dans les peptides phosphorylés du mélange initial, a mis en évidence une augmentation de $415 \%$.

c) Teneur en acide $N$-acétylneuraminique des fractions des caséinomacropeptides

Les dosages de l'acide $\mathrm{N}$-acétylneuraminique (NANA) des CMP totaux et des fractions I et II permettent d'évaluer les teneurs en caséinomacropeptides et glycomacropeptides des deux fractions (tabl. 6). La teneur en NANA passe de $6,76 \%$ des protéines $(\mathrm{N} \times 6,38)$ dans le mélange initial à $9,32 \%$ des protéines dans la fraction II, soit une augmentation de $38 \%$, alors que la teneur en NANA de la fraction I ne représente que $1,46 \%$ des protéines. 


\section{TABLEAU 5}

Teneurs en phosphore des peptides de caséines, des peptides phosphorylés et non phosphorylés et des fractions I et II des phosphopeptides obtenus par fractionnement chromatographique sur un support échangeur d'anions

Phosphorus contents of casein peptides, phosphopeptides and peptides without organic phosphorus and fractions $I$ and II of the phosphopeptides obtained by chromatographic separation on an anion-exchange support

\begin{tabular}{l|c|c}
\hline \multicolumn{1}{c|}{ Nature des peptides } & $\begin{array}{c}\text { Teneur } \\
\text { en phosphore } \\
\text { (mg/100 g peptides })\end{array}$ & $\begin{array}{c}\text { Teneur } \\
\text { en phosphore } \\
(\mathrm{mg} / 100 \mathrm{~g} \mathrm{~N} \times 6,38)\end{array}$ \\
\hline Peptides de caséine & 0,63 & 0,50 \\
\hline Peptides non phosphorylés & 0,08 & 0,06 \\
\hline Phosphopeptides & 3,62 & 2,38 \\
\hline $\begin{array}{l}\text { Phosphopeptides } \\
\text { Fraction I }\end{array}$ & 0,05 & 0,03 \\
\hline $\begin{array}{l}\text { Phosphopeptides } \\
\text { Fraction II }\end{array}$ & 5,23 & 9,89 \\
\hline
\end{tabular}

TABLEAU 6

Teneurs en acide $\mathrm{N}$-acétylneuraminique dans le mélange initial de caséinomacropeptides (CMP total) et les fractions I et II obtenues après fractionnement chromatographique sur un support échangeur d'anions

$N$-acetylneuraminic contents in the initial mixture of caseinomacropeptides (total CMP) and the fractions I and II obtained by chromatographic separation on an anion-exchange support

\begin{tabular}{l|c|c|c}
\hline \multicolumn{1}{c|}{ Fractions peptidiques } & DO à $549 \mathrm{~nm}$ & $\begin{array}{c}\text { NANA } \\
(\mathrm{g} / 100 \mathrm{~g} \text { de } \\
\text { peptides })\end{array}$ & $\begin{array}{c}\text { NANA } \\
(\mathrm{g} / 100 \mathrm{~g} \\
\mathrm{N} \times 6,38)\end{array}$ \\
\hline CMP Total & 0,59 & 5,07 & 6,76 \\
\hline Fraction I & 0,11 & 0,93 & 1,46 \\
\hline Fraction II & 0,79 & 6,83 & 9,32 \\
\hline
\end{tabular}

2. Caractérisation par chromatographie liquide haute performance (HPLC) en phase inverse

Les profils chromatographiques obtenus avec les peptides de lactosérum et les phosphopeptides sont présentés figures 3 et 4 . Les fractions I contiennent généralement la totalité ou presque des acides aminés libres du mélange peptidique initial, qui sont élués au cours des dix premières minutes. Les 
peptides contenus dans les fractions I, sont élués au cours des 30 premières minutes, ce qui correspond à la zone hydrophile ou faiblement hydrophobe du gradient.

Les peptides contenus dans les fractions II sont élués dans la zone la plus hydrophobe du gradient.

Les fractions glycosylées et non glycosylées des caséinomacropeptides sont éluées dans la zone hydrophobe du gradient.

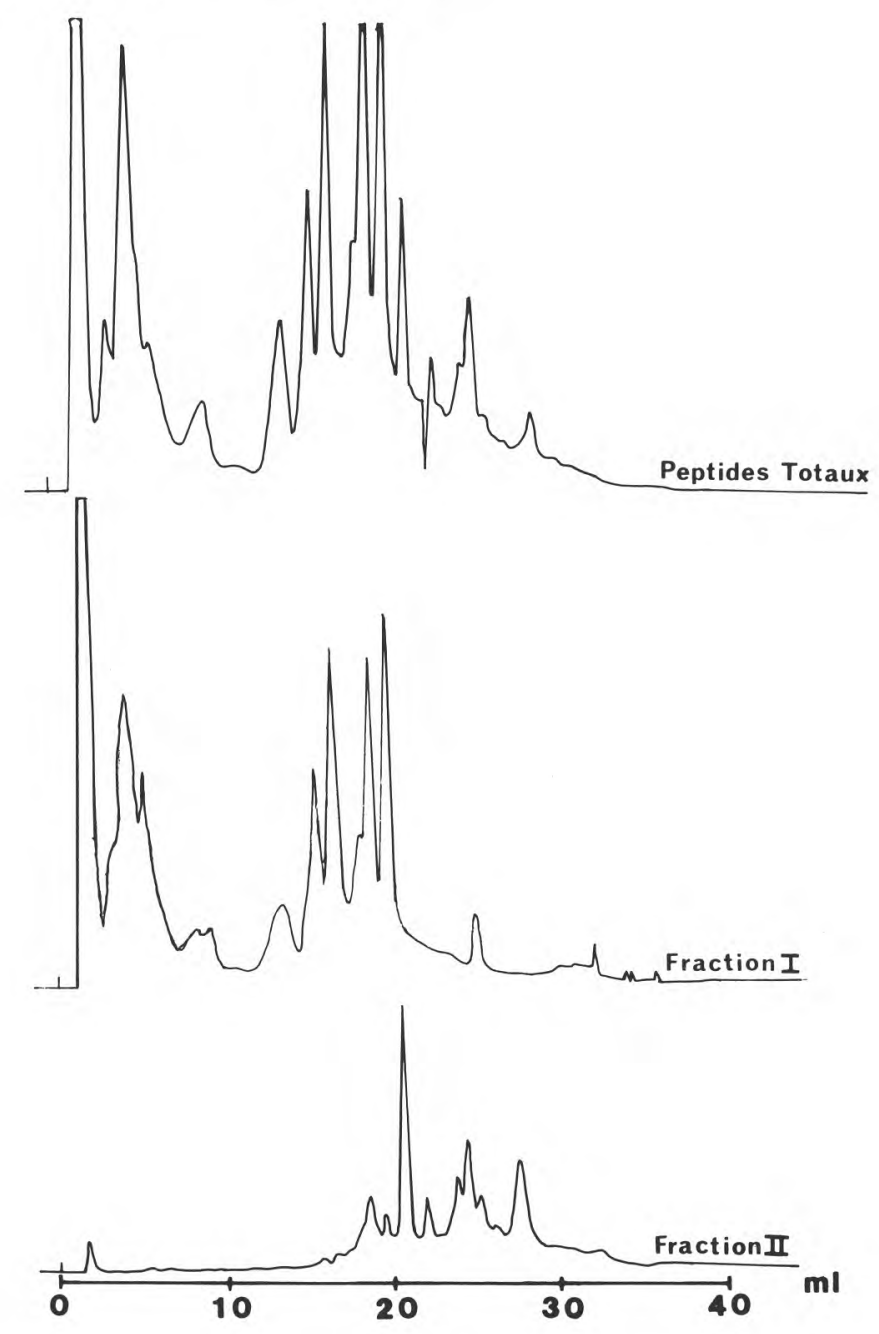

Fig. 3

Profils d'élution des fractions peptidiques de lactosérum (peptides totaux, fractions I et II) en chromatographie phase inverse.

Elution profiles of whey peptides fractions (total peptides, fractions I and II) in reverse phase chromatography. 


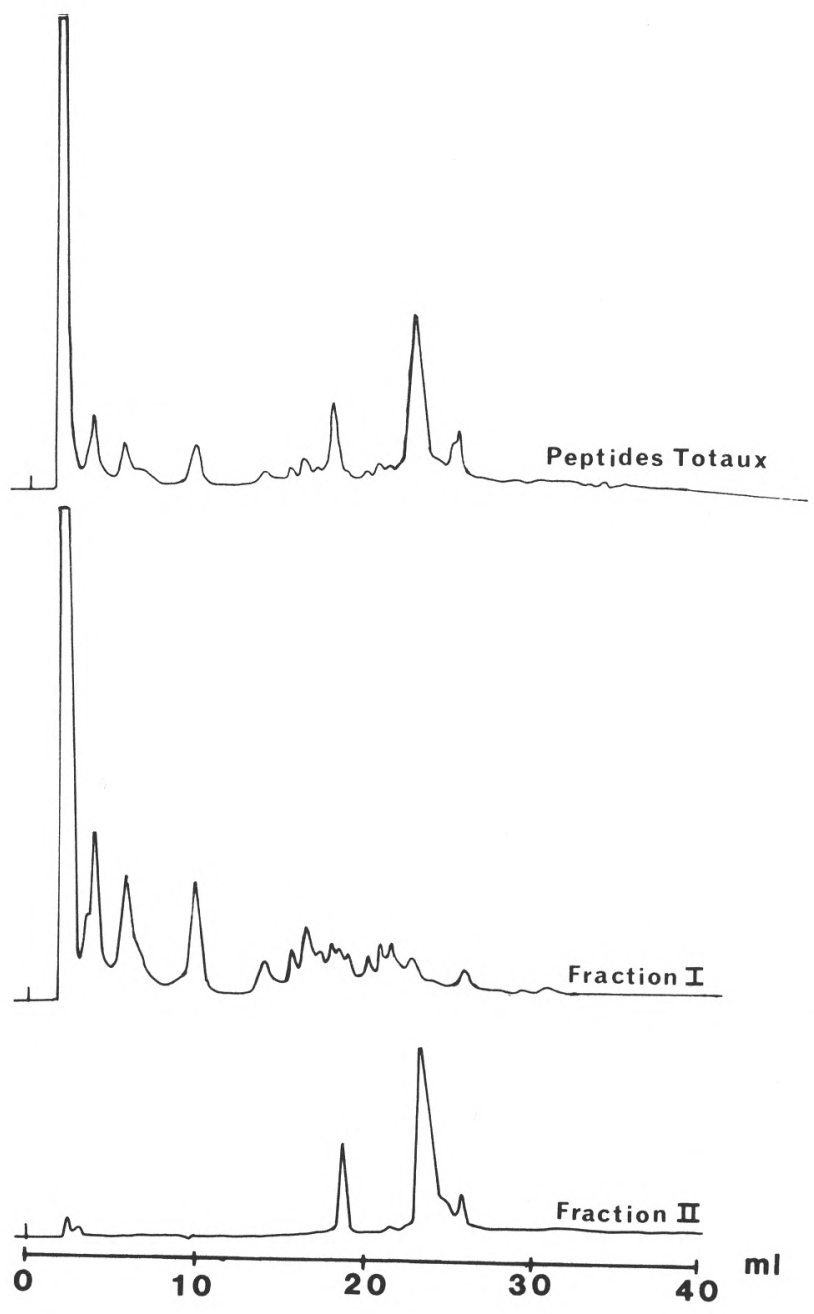

Fig. 4

Profils d'élution des fractions des phosphopeptides (peptides totaux, fractions I et II) en chromatographie phase inverse.

Elution profiles of phosphopeptides fractions (total peptides, fractions I and II) in reverse phase chromatography. 


\section{Discussion}

Le fractionnement préparatif des peptides issus de l'hydrolyse enzymatique des protéines de lait en deux fractions, différentes par leur $\mathrm{pHi}$ et par leur affinité pour l'eau, est réalisable par chromatographie frontale d'échange d'ions. Quelle que soit la matière première mise en œuvre (hydrolysats de caséine ou de protéines de lactosérum), la seconde fraction (celle fixée par le support) est non seulement enrichie, par rapport au produit initial, en peptides à faible $\mathrm{pHi}$ (responsable de la fixation sur le support anionique), mais aussi en peptides hydrophobes comme cela est mis en évidence par le comportement en chromatographie analytique phase inverse de cette fraction.

L'hydrophobicité relative du mélange peptidique composant la fraction II ne repose pas sur une teneur nettement différenciée en résidus à très faible affinité pour l'eau tels que leucine et isoleucine (cf. fig. 2), mais probablement sur une plus grande proportion de peptides longs, hypothèse déjà émise par Carles et Ribadeau-Dumas (1986) à partir de l'analyse des hydrolysats de caséine $\beta$. Cette plus grande proportion de peptides longs se trouve également supportée par les résultats que nous avons obtenus en chromatographie d'exclusion. Le temps de rétention des pics correspondant à la fraction II était toujours inférieur à celui des pics correspondant à la fraction I et leurs surfaces, pour une même quantité injectée, plus faibles. Or, ces surfaces résultent d'une détection par fluorimétrie moléculaire après réaction de l'orthophtalaldehyde avec les seules extrémités $\mathrm{ND}_{2}$ terminales.

L'enrichissement constaté dans la fraction II en phosphore et en sérine, lors de la chromatographie sur échangeur d'anions, des hydrolysats totaux de caséine ou des peptides phosphorylés est à relier à l'électronégativité des résidus phosphosérine au nombre de 8-9 pour la caséine $\alpha_{51}, 10-13$ pour la caséine $\alpha_{s 2}$ et 5 pour la caséine $\beta$, électronégativité qui entraîne leur fixation sur le support.

La chromatographie frontale sur échangeurs d'anions permet aussi une séparation aisée des formes non glycosylées et glycosylées du caséinomacropeptide, ces dernières ayant une plus grande affinité pour le support du fait de la présence de $\mathrm{N}$-acétylgalactosamine et d'acide $\mathrm{N}$-acétylneuraminique (FouRNET et al., 1979 ; Salto et al., 1981). La différence de composition entre fraction I et II ne porte pas sur les acides aminés comme le montre la faible valeur du paramètre de Marchalonis et WeLtMAn (1971) (tabl. 3), mais sur les teneurs en résidus glycosylés et notamment en NANA (tabl. 6).

La chromatographie frontale sur échangeurs d'ions est aisée à mettre en œuvre à grande échelle et son coût de fonctionnement est relativement faible du fait de la non-utilisation des tampons. Elle permet d'obtenir une première séparation, certes limitée, des mélanges peptidiques issus de l'hydrolyse de protéines laitières en mélange, mais qui peut trouver sa justification dans la préparation de produits à usage diététique.

La caractérisation fine des peptides composant les fractions résultant de la séparation sur échangeurs d'ions n'est pas évidente en raison de la complexité des hydrolysats mis en œuvre. Il est évident que cette caractérisation serait 
facilitée si les produits chromatographiés résultaient de l'hydrolyse de protéines individuelles purifiées. Il pourrait alors être mis à profit la spécificité d'action des enzymes utilisées et les connaissances acquises ces dernières années sur les séquences des protéines laitières : caséine $\alpha_{\mathrm{S} 1}$ (Mercier et al., 1971), caséine $\alpha_{s 2}$ (BRignon et al., 1977), caséine $\beta$ (Ribadeau-Dumas et al., 1972), caséine K (Mercier et al., 1973), $\alpha$-lactalbumine (BREw et al., 1973) et $\beta$-lactoglobuline (Braunitzer et al., 1972). Cela suppose évidemment que soient mises au point des technologies industrialisables permettant l'isolement à grande échelle de protéines individuelles purifiées. De tels procédés commencent à se mettre en place au moins pour les protéines sériques (PIERre et Fauquant, 1986) et il est permis d'espérer qu'ainsi pourront être préparées des fractions peptidiques économiquement intéressantes et répondant à l'attente des industries de la pharmacie et de la diététique.

Reçu le 21 juillet 1986

Accepté pour publication le 20 mars 1987

\section{Références bibliographiques}

Brantl V., Henschen A., 1979. Novel opioid peptides derived from casein. Isolation and Structure. Physiol. Chem., 360, S, 1211-1224.

Braunitzer G., Chen R., Schrank B., Stangl A., 1972. Automatic sequence analysis of a protein ( $\beta$-lactoglobulin AB). Hoppe Seyler's Z. Physiol. Chem., 353, 832-834.

Brew K., Castellino F.J., Vanaman T.C., Hill R.L., 1973. The complete aminoacid sequence of bovine $\alpha$-lactalbumin. J. Biol. Chem., 247 (17), 4570-4582.

Brignon G., Ribadau-Dumas B,, Mercier J.C,, Pelissier J.P., 1977. Complete aminoacid sequence of bovine $\alpha \mathrm{s}_{2}=$ casein. FEBS Lett., 76 (2), 274-279.

Brulé $G_{+}, 1981$. Résultats non publiés.

Brulé G., Maubois J.L., Fauquant J., 1974. Etude de la teneur en minéraux des produits obtenus lors de l'ultrafiltration du lait sur membrane. Lait, 54, 600-615.

Brulé G., Roger L., Fauquant J., Piót M., 1981. Procédé de traitement d'une matière à base de caséine contenant des phosphocaséinates de cations monovalents ou leurs dérivés, produits obtenus et applications. Brevet Français $\mathrm{n}^{\circ}$ 80-02-281.

Carles C., Ribadeau-Dumas B,, 1986. Determination of gradient elution conditions for the separation of peptide mixtures by reversed-phase high-performance liquid chromatography: bovine $\beta$-casein tryptic digest. J. Dairy Res., 53, 595-600.

Fournet B., Fiat A.M., Alais C., Jolies P., 1979. Cow $\kappa$-casein : structure of the carbohydrate portion. Biochim. Biophys. Acta, 576, 339-346.

Levy E., 1976. Alimentation entérale continue, Principe-Technique-Indications-Résultats. Aliment. Vie, 64 (4), 235-256.

Marchalonis J.J., Weltman J.K., 1971. Relatedness among proteins : a new method of estimation and its application to immunoglobulins. Comp. Biochem. Physiol., 38 B, 609-625.

Maubois J.L., Roger L., Brulé G., Piot M., 1979. Hydrolysat enzymatique total de protéines de lactosérum. Obtention et applications, Brevet Français INRA, ${ }^{\circ}$ 79-16-482.

MENDY F., 1976. Diététique thérapeutique et réanimation entérale à faible débit continu. Conceptions des produits. Aliment. Vie, 64 (4), 265-285.

Mendy F., 1984. Fragmentation des protéines laitières. Biofutur, 24, 60-61. Interview de J. Rajnchapel-Messai. 
Mendy F., Brachfogel N., Spielmann D., 1981. Actualités dans le domaine de la connaissance, de l'utilisation digestive et métabolique en nutrition humaine des protéines laitières. Colloque INRA-CNIEL. Rev. Lait. Fr. (400), 37-57.

Mercier J.C., Grosclaude F., Ribadeau-Dumas B., 1971. Structure primaire de la caséine $\alpha \mathrm{s}_{\text {, }}$ bovine. Eur. J. Biochem., 23, 41-51.

Mercier J.C., Brignon G., Ribadeau-Dumas B., 1973. Structure primaire de la caséine к B bovine. Séquence complète. Eur. J. Biochem., 35, 222-235.

Pierre A., Fauquant J., 1986. Principes pour un procédé industriel de fractionnement des protéines du lactosérum. Lait, 66, 405-419.

Rerat A., Lacrois M., Simoes-Munes C., Vaugelade P., Vaissade P., 1984. Absorption intestinale comparée d'un mélange d'hydrolysats ménagés de protéines laitières et d'un mélange d'acides aminés libres de même composition chez le porc éveillé. Bull. Acad. Natl. Med., 168, 385-391.

Ribadeau-Dumas B., Brignon G., Grosclaude F., Mercier J.C., 1972. Structure primaire de la caséine $\beta$ bovine (séquence complète). Eur. J. Biochem., 25, 505-514.

ROGER L., 1979. Contributions à la recherche d'une meilleure utilisation en alimentation humaine des composants glucidiques et protéiques du lactosérum grâce à l'emploi des techniques à membranes. Thèse de Doctorat de $3^{\mathrm{e}}$ cycle, Rennes (ENSAR).

Saito T., Iтон S., Adachi S., 1981. The chemical structure of tetrasaccharide containing Nacetylglucosamine obtained from bovine colostrum к-casein. Biochim. Biophys. Acta, 673, 487-494.

Silk D.A., Fairclough P.D., Clark M.L., Hegarty J.E., Clegg K.M., Matthews D.M., 1980. Use of a peptide rather than free amino acid nitrogen source in chemically defined « elemental » diets. J. Parenter. Enter. Nutr., 4 (6), 548-553.

Sleisinger M.H., Burston D., Dalrymple J.A., Wilkinson S., Mathtews D.M., 1976. Evidence for a single common carrier for uptake of a dipeptide and a tripeptide by hamster jejunum in vitro. Gastroenterology, 71, 76-81.

Warren L., 1959. The thiobarbituric acid assay of sialic acids. J. Biol. Chem., 234, 8, 1971-1975. 